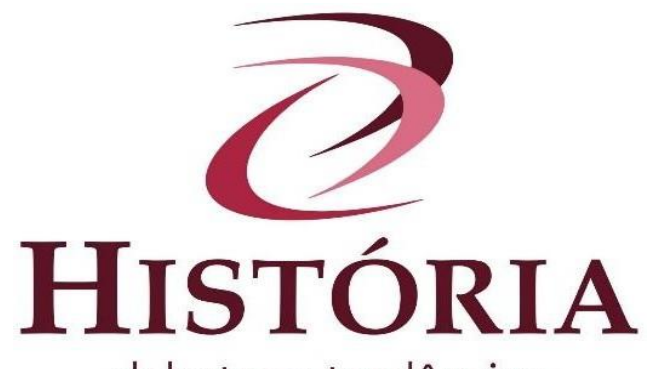

\title{
História Global: o novo encontro entre a História e as Ciências Sociais
}

\author{
Global History: the new encounter between History and the Social Sciences
}

\section{Historia Global: el nuevo encuentro entre la Historia y las Ciencias}

\author{
Sociales
}

Patrícia Mara Cabral de Vasconcellos ${ }^{\mathrm{i}}$

\begin{abstract}
Resumo: O artigo tem por objetivo elencar as premissas teórico-metodológicas da corrente historiográfica denominada de História Global e como tais preceitos se conjugam em um novo encontro entre a história e as ciências sociais. O método é dedutivo, baseado em pesquisa bibliográfica. O material de análise é referente à produção bibliográfica, em especial, de autores do campo de estudo da história sobre a "História Global" e das ciências sociais, os que versam sobre os debates teóricos da "globalização". O reencontro entre a história e as ciências sociais reabre a área das ciências humanas para uma leitura dinâmica da sociedade e proporciona um repensar sobre a construção do conhecimento.
\end{abstract}

Palavras-chave: Ciências Sociais. História Global. Metodologia.

\begin{abstract}
The article aims to list the theoretical and methodological premises of the historiographic current called Global History and how these precepts come together in a new encounter between history and the social sciences. The method is deductive and based on bibliographical research. The material of analysis refers to the production of literature, particularly that of authors from the field of the study of history, on "Global History" and the social sciences, i.e., those who deal with the theoretical debates of "globalization". This reencounter between history and the social sciences reopens the area of human sciences for a dynamic reading of society and provides a rethinking about the construction of knowledge.
\end{abstract}

Keywords: Social Sciences. Global History. Methodology.

Resumen: El artículo pretende enumerar las premisas teórico-metodológicas de la corriente historiográfica llamada Historia Global y cómo estos preceptos se unen en un nuevo encuentro entre la historia y las ciencias sociales. El método es deductivo, basado en la investigación bibliográfica. El material de análisis se refiere a la producción bibliográfica, en particular, de autores del campo de estudio de la historia sobre la "Historia Mundial" y las ciencias sociales, los que se ocupan de los debates teóricos de la "globalización". El reencuentro entre la historia y las ciencias sociales reabre el área de las ciencias humanas para una lectura dinámica de la 
sociedad y proporciona un replanteamiento sobre la construcción del conocimiento.

Palabras clave: Ciencias Sociales. Historia Global. Metodología.

\section{Introdução}

Na busca por identificar na literatura das Ciências Sociais internacional a origem e os usos do termo "história global", Ficker (2014) realizou uma pesquisa nos títulos das obras das bibliotecas do Colegio de México e da Universidade de Stanford e constatou que os primeiros trabalhos que utilizaram o termo "global" com precisão dataram do início dos anos 1990. Desde então houve vários esforços para fomentar o debate e apresentar uma definição sobre as premissas teórico-metodológicas da história global. Do ponto de vista da literatura, a Revista dos Annales, na França, apresentou na primeira edição do ano de 2001, artigos que discutiram a temática - a história em escala global. No Brasil, as principais iniciativas foram mais recentes. Em 2014, a Revista Brasileira de História publicou o dossiê sobre "O Brasil na História Global” na sua edição no. 68 e a Revista Estudos Históricos, na edição n.60 de 2017 publicou o dossiê "Perspectivas Globais e Transnacionais".

Contudo, ressalta-se que, ao longo de trinta anos, apresentar uma definição sobre história global não é tarefa simples. Não obstante, mesmo diante de divergências sobre seu conceito, pode-se afirmar que suas premissas teórico-metodológicas baseiam-se na combinação de métodos diferentes da História e das Ciências Sociais, preceituando a não separação sistemática entre as disciplinas. Evoca-se a interdisciplinaridade, afirmando-se que, somente assim, é possível constituir uma pesquisa em história global. Dessa forma, parte-se do pressuposto que é no encontro entre a História e as Ciências Sociais que as respostas aos desafios da sociedade global ou fluxos globais serão analisadas. É a interdisciplinaridade entre a História e a Ciências Sociais que colabora para indicar as propostas metodológicas e os novos caminhos para a pesquisa diante dos fluxos globais.

Para compor a análise, o artigo divide-se em três partes. Na primeira, o objetivo é apresentar como os fluxos globais impulsionaram um novo modo de pensar a pesquisa social e a historiografia. Na busca das premissas da história global e dos desafios a que se propõe, indicam-se quais seriam suas contraposições com a micro história e quais as aproximações com as Ciências Sociais, quando esta insere os estudos sobre globalização.

Na segunda parte, recorre-se aos fundamentos teóricos-metodológicos na perspectiva de Fernand Braudel e Immauel Wallerstein, dois autores tidos como fundadores da abordagem da história global para, através de seus conceitos de história total e sistema-mundo, 
respectivamente, avaliar como a união entre a História e as Ciências Sociais tornou-se primordial para fomentar o entendimento da sociedade complexa e global.

Por fim, argumenta-se sobre quais são as principais premissas teórico-metodológicas que constituem a história global. Apresentam-se cinco premissas que resumem os embates e as interconexões entre as áreas de conhecimento. Torna-se evidente que a fragmentação disciplinar não colabora o suficiente para os objetivos a que se quer alcançar ao propor uma história global. Delineia-se o reencontro entre História e as Ciências Sociais para valorizar e validar os procedimentos metodológicos.

Dessa forma, entende-se que a história global também pode ser vista como um "reequilíbrio" entre as Ciências Sociais e a História (VENGOA, 2009) de forma que esta não esteja limitada a observar as análises empreendidas pela sociologia e, tampouco, as Ciências Sociais estejam excluídas dos estudos históricos.

\section{Por que uma História Global? A História, as Ciências Sociais e os tempos globais.}

A nomenclatura História Global surge no final da década de 1980 e início de 1990. Inicialmente, sob este prisma, as discussões concentram-se em estudos sobre a grande divergência, o choque de civilizações ou as modernidades múltiplas. $\mathrm{O}$ interesse em postular uma nova história tanto pode ser encontrado no fenômeno da globalização, sugerindo que a História deve atentar-se para os fluxos globais, em certa contraposição ao referencial nacional, quanto ao retorno de análises em que prevaleçam a visão sobre as estruturas abrangentes ou as grandes sínteses, neste caso, um movimento inverso ${ }^{\text {ii }}$ à abordagem historiográfica postulada pela micro-história ${ }^{\text {iii }}$.

De imediato é importante destacar que a história global não se confunde com o processo denominado de globalização e não necessariamente está a ele vinculado enquanto fenômeno que compõe a sociedade capitalista do século XXI. Contudo, a complexidade da sociedade global desperta a necessidade de revisar paradigmas teóricos metodológicos nas ciências humanas, questionando-se a fragmentação da produção historiográfica, o uso do tempo linear e a centralidade do Estado nacional ou de análises sociológicas enraizadas na sociedade nacional.

Assim, para melhor compreender a questão deve-se procurar entender o que é a globalização e como ela impacta na produção do conhecimento. Neste sentido, segundo Ortiz (2009), desde o final dos anos 80 e início dos anos 90, as Ciências Sociais se debruçam em 
refletir sobre o fenômeno. Entretanto, um conceito que possa expressar o significado de globalização é buscado por pesquisadores de diversas áreas, historiadores, sociólogos, antropólogos, economistas, cientistas políticos entre outros e, ainda que não haja uma definição unívoca, todas pronunciam que há algo novo (ORTIZ, 2009). Giddens, por exemplo, parte da seguinte definição:

A globalização pode assim ser definida como a intensificação das relações sociais em escala mundial, que ligam localidades distantes de tal maneira que acontecimentos locais são modelados por eventos ocorrendo a muitas milhas de distância e vice-versa. Este é um processo dialético porque tais acontecimentos locais podem se deslocar numa direção anversa às relações muito distanciadas que os modelam. A transformação local é tanto uma parte da globalização quanto a extensão lateral das conexões sociais através do tempo e do espaço. (GIDDENS, 1991, pg 60)

Tais transformações inseridas pela globalização impactam na formulação das ciências humanas. Para Ianni $(1998 ; 2001)$ a globalização impõe desafios das ciências sociais quanto ao objeto, aos procedimentos de pesquisa e ao conhecimento acumulado. Isto porque o fenômeno apresenta-se como uma ruptura histórica, na qual as relações, processos e estruturas sociais manifestam-se em escala mundial. Assim, explicita o autor:

No âmbito da globalização, ou do globalismo visto como uma totalidade históricoteórica, reabrem-se os contrapontos, as continuidades e as descontinuidades, sintetizados em noções tais como: sujeito e objeto do conhecimento, parte e todo, passado e presente, espaço e tempo, singular e universal, micro teoria e macro teoria (IANNI, 1998, s/n)

Para Ortiz, o que mais dificultou a compreensão da globalização é que não se tratava de um novo tema, mas um fator que questionava a validade das categorias sociológicas como classe social, nação e identidade nacional. Ou seja, na nova configuração social, novas categorias de análise precisavam ser ponderadas.

A própria forma como as ciências sociais latino-americanas se constituíram enquanto temáticas que privilegiavam o arcaico/moderno tornou-se questionável, vez que os fluxos globais atravessam o tempo e local sem distinção. Não se trata mais de uma temporalidade progressiva em que o ser moderno era o caminho (ORTIZ, 2009, p.233-234). A origem do pensamento social nos países centrais (Estados Unidos, França, Alemanha, por exemplo) e na América Latina é marcada por ritmos diferentes, uma vez que postulados diante da problemática da modernidade. Enquanto nos países centrais discutia-se a industrialização e a racionalização, nos trópicos as temáticas centravam-se na sociedade rural, nas oligarquias e na construção de um Estado nacional (ORTIZ, 2009). Com raiz na teoria funcionalista, havia um caminho para 
o progresso e as bases teóricas latino-americanas espelhavam o porvir do futuro capitalismo industrial moderno. Somente com o declínio do pensamento pós-moderno, a problemática da globalização se torna proeminente nas Ciências Sociais.

No campo da história, se em alguma medida a imposição por uma história global resulta da globalização, do ponto de vista historiográfico, uma afirmativa contestável, mas recorrentemente aplicada, é de que a história global, em consequência, é uma contraposição da chamada micro-história.

Na obra "Herança Imaterial", Giovanni Levi, que adota a perspectiva da microhistória, propõe uma mudança do ponto de vista na análise, em uma crítica aos modelos estruturalista e funcionalista e quer compreender a comunidade do Piemonte do século XVII, com base nas relações sociais de seus habitantes (LEVI, 2000). A ideia é revelar a complexidade de tais relações.

Há um fundamento similar quando se busca compreender a complexidade derivada de uma sociedade global - a micro-história propõe uma redução na escala de observação; procura analisar como funciona a sociedade na sua base (o que pode ser entendido como "local") e, através desses dados, generalizar conclusões com o intuito de gerar perguntas e respostas capazes de serem comparáveis em outros contextos.

Mesmo com escalas de observação diferentes, a micro-história e a história global não caminham em sentido totalmente oposto. Bohorquez (2018), por exemplo, apresenta como a escala da micro-história pode ser uma opção metodológica para resolver problemas da história global. Entende o autor que nas últimas décadas a pesquisa na história tem sido impactada pelo "giro global", ou seja, por uma perspectiva de interpretação que se coloca além do Estado-nação e das delimitações de áreas culturais. Em consequência, deve-se pensar o mundo com mais movimento em que elementos como interconexão, circulação, cruzamentos e fluxos se destacam. Em outras palavras, significa que em termos de marco temporal, busca-se construir uma história não linear. Em comum, influencia tanto a perspectiva local quanto global, ainda que, para a micro-história, a ênfase resida em uma análise de curta duração e para a história global o foco esteja nas análises de longos períodos históricos (TRIVELLATO, 2011).

Para a micro-história pode-se observar como o local se conecta e é estruturado (a todo instante) pelas cadeias de interações que se constroem além do espaço local. Neste caso, a análise centra-se na forma como o(s) sujeito(s) responde(m) às cadeias de interação e causalidade. Visto dessa forma, o debate contribui quando a construção do local se torna chave para entender o global, respaldado na figura do sujeito que se move no mundo global. Dessa forma, quando a micro-história é vista como uma metodologia que conjuga processos temporais 
e geográficos para propor e responder questões maiores (sociais), ela não é o oposto da história global. Pelo contrário, suas contribuições metodológicas tornam-se úteis, inclusive, se na pesquisa for possível adotar um movimento de pêndulo entre três perspectivas: a local, a nacional e a global, configurando os espaços nos quais os agentes se movem ${ }^{\text {iv }}$.

Parte do que é vislumbrado pela história global já era feito pela micro-história se o objetivo é perceber as interações entre os indivíduos. Contudo, a história global ao alterar a escala de observação também frisa as peculiaridades estruturais que nem sempre são apreendidas na escala reduzida.

De fato, a globalização impele por uma nova forma de ver os problemas sociais (VENGOA, 2009), ou seja, muda os quadros de pensamento (GRUZINSKI,2001). Assim, as argumentações em torno da temática, seja na História ou nas Ciências Sociais, apontam para a necessidade de uma investigação sobre os pontos positivos e as limitações dos procedimentos teórico-metodológicos tradicionais. A seguir propõe-se superar as fronteiras disciplinares entre a História e a Ciências Sociais para indicar propostas metodológicas e, por conseguinte, novos caminhos para a pesquisa.

\section{História e Ciências Sociais: o desafio de superar as fronteiras disciplinares.}

Segundo Kocka (2012), a história global surge preceituando novas formas de cooperação entre a História e as Ciências Sociais, principalmente por conta do interesse da análise das estruturas abrangentes e dos processos de larga escala. É uma perspectiva oposta àquela pensada no século XIX, quando a história se formava enquanto disciplina especializada e privilegiava as abordagens históricas nacionais (KOCHA, 2012). Recorda-se que foi no século XIX que o conhecimento disciplinar foi privilegiado (SCHIMANSKI, 2013). Naquele momento, segundo Schwartzan (1997), as humanidades de um lado e as ciências de outro foram vistas como esferas separadas e estanques, cujas diferenças se acentuavam conforme: a quantidade de informação; a especialização que era requerida por cada uma; a diferença de estilo cognitivo e a diferença de modelo intelectual.

Contudo, ao longo do tempo, constatou-se que os problemas complexos não eram respondidos satisfatoriamente no isolamento disciplinar. Para produzir um conhecimento sobre o meio social e inserir a possibilidade de mudanças foi preciso, entre outras características, ir além do trabalho de pesquisa com perfil disciplinar.

Assim, ao pensar a origem da construção de uma abordagem da história global, dois 
autores se destacam, inclusive quanto à afirmação de união entre a História e as Ciências Sociais: o historiador francês Fernand Braudel e sociólogo norte-americano Immanuel Wallerstein.

$\mathrm{Na}$ Europa, seguindo a tradição historiográfica francesa, Fernand Braudel é considerado um dos precursores da história global (FICHER, 2014). A história total de Braudel é referência ao menos por dois motivos: 1) propor transcender a separação convencional das disciplinas das ciências sociais; 2) propor compreender de modo abrangente os processos históricos, analisando os acontecimentos históricos na perspectiva da longa duração.

Braudel (1965), no artigo "História e Ciências Sociais - a longa duração" demonstra sua preocupação com a separação das disciplinas, os dilemas das fronteiras que separam ou aproximam uma ciência da outra, ou no caso, da história das disciplinas vizinhas. Para o autor, a tentativa de encontrar um "mercado comum" e experimentá-lo seria uma operação urgente, dado o acúmulo de conhecimentos e a necessidade de um trabalho coletivo, ainda que, posteriormente, cada ciência retomasse sua especificidade.

A contribuição da História, segundo o autor, seria fornecer uma compreensão do tempo da duração social, ou seja, os "tempos múltiplos e contraditórios da vida do homem" (BRAUDEL, 1965, p.262). Ao especificar sua argumentação, Braudel reafirma que, para compreender a pluralidade do tempo social, deve-se pensar em uma metodologia comum. Neste caso, o tempo longo ou a longa duração seria especialmente interessante para unir as Ciências Sociais e a História.

Dialogando com o antropólogo Levi-Strauss, Braudel reconhece a importância das estruturas sociais, mas adiciona o elemento do tempo histórico para compor o que seria a história estrutural. Assim, sintetiza Silva sobre as características desta história:

\footnotetext{
Ela se interessa pelo que se repete e é quase imutável, desloca o excepcional em nome dos elementos regulares e enfatiza a descrição do cotidiano na longa duração; é uma história das "populações totais", contempla todos os segmentos de uma sociedade e se caracteriza pela demarcação de descontinuidades, vista como a subversão de uma estrutura e o advento de uma nova configuração social, embora se trate de uma revolução silenciosa, imperceptível. (SILVA, 2005, p. 145).
}

Como dito, a contribuição de Braudel para a abordagem da história global está na investigação das estruturas abrangentes e na metodologia de união das ciências humanas. Estes são elementos essenciais, mas não únicos, do que compõe a história global.

Gerstenberger (2013), por exemplo, questiona se a obra do sociólogo brasileiro Gilberto Freyrev , contemporâneo de Braudel, pode enquadrar-se na denominação de história 
global. Gerstenberger (2013) analisa, em especial, os livros "Casa Grande e Senzala" e "Sobrados e Mucambos" para identificar pontos que aproximam ou afastam o autor do respectivo enquadramento, baseando-se, inclusive, nas críticas de Braudel à obra de Freyre. Em síntese, há sete pontos que o aproximam: a) pluralismo de métodos e técnicas; b) uma pesquisa que combina abordagens de diferentes ciências (sociologia, psicologia, antropologia e história, por exemplo); c) crítica à produção histórica "imperial” ou reivindicação de uma história para a periferia; d) a ênfase na região em termos culturais e do cotidiano sendo mais importante que a nação; e) metodologia inovadora, inclusive, pensando uma primeira globalização que remeteria aos efeitos da colonização do século XVI; f) crítica à utilização de categorias analíticas grandes e abstratas ${ }^{\mathrm{vi}}$, preferindo avaliar na perspectiva do microcosmo; g) promove a microperspectiva na análise de processos da globalização.

Por outro lado, baseando-se na crítica feita por Braudel, relata a autora que na obra de Freyre não haveria homens se movimentando, uma vez que ele concentra a análise na população estável ou sedentária. Como visto, a história global procura evidenciar as conexões e interações. Ainda segundo Braudel, Freyre promove uma homogeneização das regiões, subestimando diferenças entre as mesmas. Há um direcionamento na análise para revelar uma unidade nacional. Por tais razões Freyre é classificado como um historiador nacional e não história global, mesmo que em sua obra verse temas como miscigenação, culturas e colonização que podem ser percebidos nos processos de globalização (BRAUDEL apud GERSTENBERGER, 2013).

Diante disto, um questionamento é colocado de modo pertinente pela autora. A história global é movida pelo desejo de descobrir padrões comuns em todas as sociedades, em escala global? Ainda que a resposta permaneça em aberto, o ponto que se consolida é a constatação de que "São os métodos e os meios e, no caso da história, também a seleção e o tratamento das fontes que sobrevivem e permanecem relevantes". (GERSTENBERGER, 2013, p.8) Sendo assim, segundo a autora, a obra Freyre contribui para a história global, uma vez que: "O potencial inovador de sua obra, na perspectiva de hoje, se encontra antes de tudo nos métodos que ele inventou, na abordagem indutiva, na pluralidade de perspectivas e em fontes que usou para entender certos aspectos da realidade social". (GERSTENBERGER, 2013, p.8). Com essa fala, reforça-se a ideia de que a história global deve ser caracterizada pelos seus métodos e premissas teóricas embasadas na interdisciplinaridade.

Já Immanuel Wallerstein, com a teoria do sistema-mundo, contribui com a percepção de história global pois aponta temporalidades diferentes constituindo uma crítica ao nacionalismo metodológico e ao paroquialismo. Entende-se o sistema mundo como uma zona 
espaço-temporal que pode abarcar unidades políticas e culturais distintas regidas por regras sistêmicas (WALLERSTEIN, 2004).

Em termos de método, ao apresentar a análise dos sistemas mundiais, o sociólogo norte-americano afirma que não se trata de uma teoria, mas de uma crítica aos pressupostos da investigação científica estipulados no século XIX (WALLERSTEIN, 1999, p.447). Dentre as críticas apresentadas pelo autor está a confrontação da divisão sistemática das disciplinas ou campos de estudo. Assim, disciplinas como antropologia, economia, ciência política e a sociologia podem contribuir muito mais se não forem vistas em esferas separadas, mas sim, sobrepostas. Na visão do sistema mundo, tais disciplinas não são arenas autônomas, pois não possuem lógicas se vistas de modo segmentado. Wallerstein é claro na sua afirmação: "Chegou a hora de atravessar esse labirinto intelectual dizendo que essas quatro disciplinas ${ }^{\text {vii }}$ são uma só" (WALLERSTEIN, 1999, p.453).

Na perspectiva da história global e dentro do sistema mundo isto significa perceber temporalidades diferentes. Tanto que outra falácia seria ver a História e as Ciências Sociais como trabalhos intelectuais distintos, como se fosse possível isolar sequências da história e universos da análise social. Para o autor, existe o cientista histórico. O problema na pesquisa, na verdade, consiste em determinar "as unidades de análise dentro das quais devemos trabalhar" (WALLERSTEIN, 1999, p.456).

Na história global está a problemática em definir o que é o global. Contudo, torna-se evidente que em sua base metodológica está a ideia de romper as barreiras disciplinares.

\section{História Global: premissas teórico-metodológicas.}

Como visto, o que se tem denominado por História Global não é algo novo. Ao contrário do que se poderia supor, a história global não é circunscrita ao contexto da sociedade global, não abarca objetos de pesquisa somente relativos ao contexto desta sociedade, nem é realizada somente a partir da década de 90. Na perspectiva sociológica, Ianni (1998) defende que uma visão global remodela a relação entre o presente e passado. Em consequência, a interpretação do passado e do presente também pode ser remodelada ou pode necessitar de novas interpretações. Isto explica porque é possível um estudo de história global sobre um passado que ainda não era o da sociedade global propriamente dita.

Subrahmanyam (2017), por exemplo, em aula inaugural no College de France, em 28 de novembro de 2013, apresenta a sua percepção sobre as origens da história global. Para tal, 
descreve trabalhos como do historiador coreano Kim Bu-sik, no século XII, ou mesmo a obra de Isidoro de Sevilha, no século VI, entre outros historiadores da antiguidade e da Idade Média, como exemplos de trabalhos que apresentam características que remetem à História Universal e que, posteriormente, já no contexto da modernidade, foram incorporadas à historiografia europeia ou pensada na Euroasia. Em síntese, para o autor, “ [...] é sobretudo no período entre 1580 e 1620 que a produção historiográfica revela uma nova ideia de história global”.

Assim, na análise da historiografia de séculos passados já se colocavam perspectivas epistemológicas a serem seguidas, como exemplo, descrever a visão do outro ou, nas palavras do autor, praticar a "xenologia", ou seja, ao apresentar a própria história deve ser capaz de reconhecer e dar voz ao outro, integrando visões de duas ou mais histórias. Esta seria uma das premissas da história universal. Por sua vez, na origem da História Global aparece a mesma preocupação, todavia centrada na figura do pesquisador. Neste caso, o historiador deve atentar para não assumir um ponto de vista (em geral, o seu de nacional) e denegrir os demais.

Pautando-se na historiografia de João de Barros ${ }^{\text {viii }}$, Subrahmanyam, (2017), destaca três pontos importantes da obra do referido autor que servem como parâmetro: primeiro, a utilização de fontes históricas não europeias; segundo, a realização da aproximação com uma história global relatada por meio de conexões e, terceiro, a apresentação de sínteses em larga escala. À vista disso, o que Subrahmanyam (2017) faz é apontar as características esperadas de uma história global.

Apesar de aspectos semelhantes, a história global não se confunde com a história mundial, universal ou com novos campos de estudo da história ${ }^{\mathrm{ix}} \mathrm{O}$ mesmo é válido para o surgimento de subáreas como história ambiental, história de gênero ou história cultural que não se constituem como novos métodos de pesquisa, mas novos campos (LEVI, 2018; BOHORQUEZ, 2018). Para Levi (2018), ainda que relacionada com outras denominações de campo de pesquisa como história conectada, história transnacional, história atlântica entre outras, a definição de história global deve ser assim compreendida:

\footnotetext{
A definição mais ampla é a que rejeita o centrismo euro-americano, que acredita que uma historiografia baseada no Estado-nação foi superada, o que sugere a idéia de que deve ser feita uma história que não imagine que as transformações são geradas apenas por dinâmicas internas, mas que tudo deve ser visto como resultado de complexas interligações relacionais fora do ponto de observação, colocando no centro as trocas, os vínculos, os fluxosx (LEVI, 2018, p.25, tradução nossa).
}

Destaca-se o objetivo de uma história que revele as complexidades dos fatos sociais e suas diversas influências, sem ter a configuração de um ponto central ou ator dominante. A 
expectativa é abarcar dimensões diferentes e vastas do fenômeno. Assim, do ponto de vista do método, a proposta é não centrar a análise em um único ponto, mas em uma rede de fatos. Um confronto analítico que impõe uma discussão sobre o entendimento de tempo, espaço e o modo de tratamento dos documentos (fontes) durante a pesquisa.

Pode-se apontar, portanto, que a história global se define, pois, pelas interações (idas e voltas constantes) entre regiões, Estados e culturas. Para tal, reelabora o espaço e utiliza de forma ímpar a noção de diferença, não a enquadrando em um marco temporal para evitar modelos homogeneizantes de comparação. Trata-se de uma história não linear.

Diante do que foi elencado anteriormente, como premissas teórico-metodológicas presentes na construção de uma pesquisa em história global, ressaltam-se cinco pontos que devem estar articulados na análise.

O primeiro ponto, como desafio para historiadores e sociólogos, está o desterritorializar, isto é, não incorrer no nacionalismo metodológico. Para Ianni (1998), com a globalização, uma das implicações epistemológicas nas Ciências Sociais deriva do fato do objeto de pesquisa, que antes se constituía, principalmente, como a realidade histórico-social nacional, se translocar para a chamada sociedade global (IANNI, 1998, s/n). Na história isto também se coloca com o que era a construção das narrativas das nações. Esta é uma mudança importante e desafiadora, pois a constituição das Ciências Sociais e da História, enquanto ciência, tem como parâmetro a sociedade nacional ou Estado-nação e a interpretação das novas configurações e dos movimentos do global, tornando difusa a perspectiva de análise, o que é uma tarefa complexa. Um olhar desterritorializado implica em mover o sujeito do conhecimento e acompanhar as diferentes perspectivas.

Como segundo ponto tem que se desocidentalizar a análise. Isto significa não promover o etnocentrismo, ou seja, preocupar-se em não hierarquizar a Europa nos espaços de análise. Na prática, por exemplo, no tratamento dos documentos (fontes), em especial de origem não ocidental, a recomendação é estar atento à cultura historiográfica, o que se explicita através do conceito de “texture". Isto significa prestar atenção aos usos e significados gramaticais, aos contextos que descrevem, às conexões entre os fatos narrados e às noções de causalidade que utilizam (LEVI, 2018). Ademais, quanto ao material da pesquisa, seria prudente não se restringir aos dados oriundos de uma biblioteca ou arquivo. Para Bohorquez (2018), produzir uma história global acarreta o custo de deslocamento para realizar a pesquisa em arquivos de diferentes áreas geográficas ${ }^{\mathrm{xi}}$.

Como consequência dos pontos anteriores, a terceira questão refere-se a deter atenção nas variações de escala ou multiplicidade de escalas. Revel (2010) afirma que as formas mais 
interessantes de história global são:

[...] aquelas que, longe de partir da ideia de que os processos sociais maiores são naturalmente globais procuram dar conta das circulações que tornaram possíveis a globalização, das conexões e das encruzilhadas, das formas de hidridação que estão na sua base e que são as únicas a torná-las compreensíveis. (Revel, 2010, p.443).

Assim, as variações de escala de observação ajudam a compreender o mundo global na medida em que revelam processos sociais amplos e, também, as suas peculiaridades. No caso, as Ciências Sociais e história devem mais atenção à articulação entre os níveis para compreender tanto uma realidade histórica maior como também a pluralidade de mundos sociais. Em outros termos, demonstrar as conexões sem aniquilar as peculiaridades.

Na quarta recomendação cita-se a preferência por histórias conectadas em oposição às histórias comparadas. Nas Ciências Sociais o uso do método comparativo, mesmo diante das considerações sobre a globalização é considerado um procedimento de pesquisa útil. No entanto, nos estudos sobre a história global, em especial na visão de Subrahmanyan, o método já não é mais pertinente para apreender as mudanças. Na visão do autor "estamos lidando com algo que não é separado e comparável, mas histórias conectadas”. (SUBRAHMANYAN, 1997, p.748, tradução nossa). Em uma crítica às ciências sociais aponta que, mesmo na visão pósmodernista, estas persistem no método - definir, descrever, classificar ou diferenciar - e que isto é um erro. (SUBRAHMANYAN, p.748).

Em contraposição ao que afirma Subrahmanyan, o sociólogo Ianni (1998) afirma que para compreender a problemática da globalização, o realizar comparações é uma premissa da pesquisa, pois faz-se necessário mapear os ângulos e tendências, o que é recorrente e o que é ruptura. Assim, o método é um passo experimental para organizar a complexidade da problemática investigada.

Por outro lado, trabalhar com a ideia de conexão tem a vantagem de afastar a noção de homogeneidade ou de elemento comum, característico do pensamento sociológico sobre globalização. Notamos como afirma Ortiz (2009) que o mundo está interconectado, o que não significa integrado. Em outras palavras, não há uma consciência comum ou universalismo.

Contribuindo para a problemática Giraud (2009) propõe a seguinte pergunta: "Em que a globalização deveria constituir um obstáculo para a comparação internacional? Não se poderia ver a comparação, ao contrário, como uma oportunidade maior de renovação dos trabalhos comparativos?” (GIRAUD, 2009, p.63). A resposta do autor centra-se em um tipo de comparação específica - a comparação dos casos mais contrastantes. Neste sentido, apresenta 
as críticas feitas ao método comparativo e os pontos que permanecem como positivos para uma comparação dos casos mais diferentes em relações internacionais. Diante da globalização, terse-ia pelo menos três consequências inter-relacionadas. Primeiro, como os fluxos globais incidem sobre todos os fatores da análise; as variáveis da comparação não são mais independentes visto que estão submetidos a uma influência recíproca ${ }^{x i i}$. A dificuldade é que o meio comum criado pelo global dificulta a independência dos casos. Segundo, a esfera estatal, base na qual primordialmente realizavam as comparações, passa a ser reformulada pelo movimento de transnacionalização. As referências não são mais somente nacionais, impulsionando para um novo enquadramento. Por último, a globalização recoloca o problema das escalas. Os processos sociais são eminentemente interativos. Com isso, há a interação entre o local e o global e uma relação multinível na vida individual e coletiva.

Todavia, se a comparação for realizada entre os casos mais contrastantes, três vantagens surgem, podendo superar as problemáticas apontadas. Primeiro, porque permite abranger na análise uma diversidade de organizações sociais. Segundo, através dos casos mais contrastantes pode-se visualizar mecanismos por vezes naturalizados, uma vez que revelam como os fenômenos funcionam, seja a religião, a educação ou os contratos. Por fim, é possível fazer uma análise profunda dos casos e das interações entre agentes e estrutura. Assim, tem-se que "as comparações em termos de casos mais contrastantes permitem entender o caráter multiescalar dos fenômenos sociais" (GIRAUD, 2009, p.71).

Por fim, a última premissa é a busca pelas estruturas abrangentes. Na sociologia, em outros termos, visam-se conceitos e interpretações de alcance global (IANNI, 1998). A dúvida é: Como compreender o todo? Ou como pergunta Ortiz (2009): É possível compreender o todo a partir do segmento? Segundo Torre (2018) deve-se esclarecer que assim como o global não é a soma das partes do local, o local não é o global visto de forma reduzida. Contudo, a dúvida vai além. Se tomarmos como base os postulados de Wallerstein, uma das críticas feitas à análise sistêmica é que esta pressupõe um grau de interação capaz de movimentar todas as partes, ou seja, elevada coesão interna e múltiplas conexões. Não obstante, visualizar ou traduzir uma realidade com a configuração descrita é um desafio ao pesquisador. Além disso, há na perspectiva sistêmica uma base teórica estruturalista que a fundamenta na emergência do modo de produção capitalista, fazendo com que as ações dos indivíduos e instituições sejam prédeterminados por tal lógica (ORTIZ, 2009). A história global, porém, poderia ser entendida como meio de outra organização social.

As cinco premissas elencadas e inter-relacionadas proporcionam uma leitura dinâmica da sociedade e proporciona um repensar sobre a construção do conhecimento. As respostas 
unidimensionais não encontram correspondência no objetivo da história global; por este sentido, é que somente uma conjugação dos fatores arrolados pode ser capaz de revelar a globalidade.

\section{Considerações finais.}

Depois de 30 anos de debates sobre globalização e história global é possível sedimentar visões e premissas teórico-metodológicas novas. O desafio que permanece é conseguir realizar a pesquisa seguindo tais parâmetros, pois se exige do pesquisador um exercício de aprendizagem constante e uma atenção ímpar nas características metodológicas. Conforme demonstrado, há questões que ainda permanecem em aberto na literatura, por exemplo, como realizar a delimitação de fluxos sociais globais ou mesmo abstrair a noção de estado nacional ou nacionalidade.

Mesmo que as pesquisas da história global ou da globalização possam, em algum momento, privilegiar um ponto da análise, dados os objetivos e procedimentos teóricos metodológicos que devem ser adotados, a sobreposição das fontes de conhecimento torna-se primordial. Constituir redes e interconexões, realizar deslocamentos e entender social e culturalmente as fontes são requisitos básicos. Isto requer atenção e múltiplos conhecimentos. Assim sendo, faz-se importante recordar que a interdisciplinaridade não se constitui, caso o fenômeno da fragmentação positivista não seja superado ou caso ocorra um reducionismo estruturalista.

O novo encontro entre a História e as Ciências Sociais reabre o campo das ciências humanas para uma visão fluída da sociedade. No mais, abre o caminho para o debate e para uma produção acadêmica que vise compreender a articulação entre estas ciências. O limite entre as Ciências Sociais, ainda em uma visão disciplinar, é muito tênue. Esquecer os limites e avançar sobre a correlação entre ambas revela um debate produtivo na promoção do conhecimento sobre a sociedade. O global relembra o pesquisador de tal fato 


\section{Referências Bibliográficas}

ANNALES. HISTOIRE, Sciences Sociales 56e Année, No. 1, Jan. - Feb., 2001. Disponível em: https://www.jstor.org/stable/i27586481.

BOHORQUEZ, J. Microglobal history: agencia, sociedad y pobreza de la historia cultural postestructural". Historia Crítica n. ${ }^{\circ} 69$ (2018): 79-98, doi: https://doi.org/10.7440/histcrit69.2018.05

BRAUDEL, Fernand. História e Ciências Sociais: a longa duração. Revista de História. V. 30 N. 62 (1965). DOI: https://doi.org/10.11606/issn.2316-9141.rh.1965.123422

FICKER, Sandra Kuntz. Mundial, trasnacional, global: Un ejercicio de clarificación conceptual de los estudios globales. Nuevo Mundo Mundos Nuevos. Débats, 2014. Disponível em: <https://journals.openedition.org/nuevomundo/66524\#quotation>. Acesso de 19 jul. 2019.

GERSTENBERGER, Debora. Gilberto Freyre: um teórico da globalização? História, Ciências, Saúde - Manguinhos, Rio de Janeiro. 2013. Disponível em: <http://www.scielo.br/hcsm.> Acesso em 15 ago. 2019.

GIDDENS, Anthony. As consequências da modernidade. São Paulo: Editora UNESP, 1991.

GIRAUD, Olivier. Comparação dos casos mais contrastantes: método pioneiro central na era da globalização. Sociologias, Porto Alegre, ano 11, no 22, jul/dez 2009, p. 54-74.

GRUZINSKI, Serge. Os mundos misturados da monarquia católica e outras connected histories. Topoi, Rio de Janeiro, mar. 2001, pp. 175-195.

IANNI, Octavio. As Ciências Sociais na época da globalização. Revista Brasileira de Ciências Sociais - Vol. 13 n³7, 1998.

IANNI, Octavio. Teorias da Globalização. Rio de Janeiro: Civilização Brasileira, 2001.

KOCKA, Jürgen. Global History: Opportunities, Dangers, Recent Trends. Culture \& History Digital Journal, 1(1) June 2012. p. 1-6, 2012.

LEVI, Giovanni. A Herança Imaterial. Trajetória de um exorcista no Piemonte do século XVII. Rio de Janeiro: Civilização Brasileira, 2000

LEVI, Giovanni. Microhistoria e Historia Global. Historia Crítica n. ${ }^{\circ} 69$ (2018): 21-35, 2018. doi: https://doi.org/10.7440/histcrit69.2018.02

LIMA, Henrique Espada. A micro-história italiana-escalas, indícios e singularidades. Rio de Janeiro: Civilização Brasileira, 2006.

MARQUESE, R.B. A história global da escravidão atlântica: esboços e perspectivas. Esboços, Florianópolis, v. 26, n. 41, p. 14-41, jan./abr.,2019.

ORTIZ, Renato. Globalização: notas sobre um debate. Sociedade e Estado, Brasília, v. 24, n. 1, p. 231-254, jan./abr. 2009. 
REVEL, Jacques. Micro-história, macro-história: o que as variações de escala ajudam a pensar em um mundo globalizado. Revista Brasileira de Educação v. 15 n. 45 set./dez. 2010 .

REVISTA BRASILEIRA DE HISTÓRIA. Dossiê: O Brasil na Historia Global. Rev. Bras. Hist. vol.34 no.68 São Paulo July/Dec. 2014.

REVISTA ESTUDOS HISTÓRICOS. Dossiê: Perspectivas Globais e Transnacionais Estud. hist. (Rio J.) vol.30 no.60 Rio de Janeiro Jan./Apr. 2017.

SANTOS JÚNIOR, J. J. G.; SOCHACZEWSKI, M. História global: um empreendimento intelectual em curso. TEMPO. Revista do departamento de História da UFF, v. 23, p. 483$502,2017$.

SCHIMANSKI, Edina. Abordagem interdisciplinar e Ciências Sociais. Revista Publicatio UEPG. Ciencias Sociais Aplicadas. v. 21, n. 1, 2013.

SCHWARTZMAN, Simon. O Sentido da Interdisciplinaridade. Publicado originalmente em Novos Estudos CEBRAP 32, março, 191-198. Publicado em A Redescoberta da Cultura, EDUSP, 1997.

SILVA, Fernando Teixeira da. História e Ciências Sociais: zonas de fronteira. História, Franca ， v. 24, n. 1, p. 127-166, 2005 . Disponível em: $<$ http://www.scielo.br/scielo.php?script=sci_arttext\&pid=S0101-

90742005000100006\&lng=en\&nrm=iso >. Acesso em: 13 nov. 2019.

SUBRAHMANYAM, Sanjay. Connected Histories: Notes towards a Reconfiguration of Early Modern Eurasia. Modern Asian Studies, Vol. 31, No. 3, Special Issue: The Eurasian Context of the Early. Modern History of Mainland South East Asia, 1400-1800 (Jul., 1997), pp. 735-762, Cambridge University Press. Disponível em: <http://www.jstor.org/stable/312798> Acesso em: 10 out. 2019.

SUBRAHMANYAM, Sanjay. Em busca das origens da História Global: aula inaugural proferida no Collège de France em 28 de novembro de 2013. Revista Estudos Históricos. volume 30, número 60, jan.-abr. de 2017. Rio de Janeiro: Centro de Pesquisa e Documentação de História Contemporânea do Brasil da Fundação Getúlio Vargas. P.219 240.

TORRE, Angelo. Micro/macro: ¿local/global? El problema de la localidade en una historia especializada. Historia Crítica n. ${ }^{\circ}$ 69, p.37-67, 2018.

TRIVELLATO, Francesca. Is There a Future for Italian Microhistory in the Age of Global History?. California Italian Studies 2, n. ${ }^{\circ}$ 1, 2011.

VENGOA, Hugo Fazio. La historia global y su conveniência para el estudio del pasado y del presente. Historia Critica Edición especial, Bogotá, Noviembre 2009, 362 pp. issn 0121-1617 pp 300-319.

WALLERSTEIN, Immanuel. Analise dos sistemas mundiais. In: GIDDENS, Anthony; TURNER, Jonathan (Org.). Teoria social Hoje. São Paulo: Ed. UNESP, 1999. 
WALLERSTEIN, Immanuel. World-Systems Analysis: An Introduction (a John Hope Franklin Center Book) (English Edition). EBook Kindle. Duke University Press Books (27 de agosto de 2004).

Submetido em: 25/03/2020

Aprovado em: 30/10/2020

Publicado: $1 \% 1 / 2021$

\begin{abstract}
${ }^{\text {i }}$ Doutora em Relações Internacionais (UnB). Professora do Departamento de Ciências Sociais da Universidade Federal de Rondônia (Unir). Professora do Programa de Pós-Graduação em Direitos Humanos e Desenvolvimento da Justiça (Unir/Emeron). Integra a Rede de Pesquisa em Política Externa e Regionalismo (REPRI). Estágio pós-doutoral no Programa de Pós-Graduação em História da Universidade Federal de Santa Maria (UFSM).
\end{abstract}

ii No sentido em que a micro história inicia a pesquisa historiográfica buscando os elementos locais (singularidades dos elementos) em uma escala de observação reduzida.

iii Felipe Espada Lima em sua obra “A Micro-História italiana - escalas, indícios e singularidades” apresenta o contexto da historiografia na Itália com a criação da revista Quaderni Storici e, em sequência, os debates e pressupostos metodológicos que embasam a micro-história.

iv Para apresentar essa alternativa Bohorquez, J. "Microglobal history: agencia, sociedad y pobreza de la historia cultural postestructural". Historia Crítica n. ${ }^{\circ} 69$ (2018): 79-98, doi: https://doi.org/10.7440/histcrit69.2018.05 cita Michael Kwass, Contraband: Louis Mandrin and the Making of a Global Underground (Cambridge: Harvard University Press, 2014), 6.

${ }^{v}$ Para a perspectiva da história global não nos interessa discorrer sobre o resultado da análise de Freyre e sobre as críticas derivadas da repercussão do postulado da "democracia racial", consequência de sua interpretação da realidade brasileira.

vi Á exemplo de categorias como "Igreja” e "opinião pública".

vii Seriam a antropologia, a economia, a ciência política e a sociologia.

viii Ver: BARROS, Joao de. Da Asia. Reimpressao, Lisboa: Livraria Sam Carlos, 1974.

ix Para aprofundar a discussão o artigo de Santos Júnior e Sochaczewski (2017) tece comparações com demais tendências historiográficas como história universal, história atlântica, história mundial dentre outras.

x Na versão original: La definición más amplia es aquella que rechaza el centrismo euroestadounidense, que cree superada una historiografía basada em el Estado-nación, que sugiere la idea de que se debe hacer una historia que no imagina que las transformaciones vienen generadas sólo de una dinámica interna, sino que todo debe verse como resultado también de complejos entrelazamientos relacionales externos al punto de observación, poniendo en el centro del interés los intercambios, los vínculos, los flujos ${ }^{\mathrm{x}}$.(LEVI, 2018, p.25)

${ }^{x i}$ Sobre esta questão a construção da pesquisa de Rafael de Bivar Marquese sobre a escravidão atlântica, é um exemplo. Ver: MARQUESE, R.B. A história global da escravidão atlântica: esboços e perspectivas. Esboços, Florianópolis, v. 26, n. 41, p. 14-41, jan./abr.,2019.

xii $\mathrm{O}$ autor parte dos estudos de Francis Galton e suas considerações sobre o método comparativo. 